\title{
The Influence of Financial Strain on Health Decision-Making
}

\author{
Oanh Kieu Nguyen, MD, MAS ${ }^{1,2,3}$, Robin T. Higashi, PhD², Anil N. Makam, MD, MAS ${ }^{1,2}$, \\ Juan C. Mijares, $B A^{2}$, and Simon Craddock Lee, $P h D, M P H^{2}$ \\ 'Department of Internal Medicine, UT Southwestern Medical Center, Dallas, TX, USA; ${ }^{2}$ Department of Clinical Sciences, UT Southwestern Medical \\ Center, Dallas, TX, USA; ${ }^{3}$, Dallas, TX, USA.
}

KEYWORDS: underserved populations; disparities; socioeconomic factors;
qualitative research.

J Gen Intern Med 33(4):406-8

DOI: $10.1007 /$ s11606-017-4296-3

(C) Society of General Internal Medicine 2018

\section{INTRODUCTION}

Despite increasing attention on addressing unmet social needs to improve chronic disease management, ${ }^{1,2}$ patient perspectives on which social needs are most important and how these needs affect health are lacking. This knowledge is essential to optimizing medical care for the most vulnerable patients. Thus we sought to explore which unmet social needs are most influential and how these needs affect individuals' decisions regarding medical treatment and self-management of health needs among communitydwelling low-income adults.

\section{METHODS}

We conducted 12 focus groups in English and Spanish among 55 adults seeking assistance at Crossroads Community Services in downtown Dallas, Texas, from July to November 2016. Crossroads is the largest non-profit food redistribution organization affiliated with the North Texas Food Bank. Participants were purposively recruited from the Crossroads waiting area. Focus groups were conducted in private using a semi-structured guide and were digitally recorded, transcribed, and translated. We conducted thematic analysis of transcripts using the constant comparative method. Data collection and analysis were conducted concurrently so that analytical insights could inform recruitment and ongoing data collection. Disagreements were resolved by negotiated consensus. We ceased recruitment upon reaching thematic saturation. The study was approved by the UT Southwestern institutional review board.

\section{RESULTS}

Most participants were in their 40s and 50s; $67 \%$ were women; $5 \%$ were white, $38 \%$ black, and $56 \%$ Hispanic. The one recurrent and unifying theme among participants

Published online January 16, 2018 was that financial strain, rather than a specific need, was the single most important factor influencing health decisionmaking. Financial strain resulted in daily weighing of trade-offs with every spending decision, not only healthrelated ones (Table 1). Although participants valued and prioritized adherence to physician-recommended therapies when possible, they employed alternative and/or selfprescribed treatments when resources were lacking.

Within this overarching theme, three key subthemes emerged:

1) Trade-offs between household and individual needs. Except in urgent or emergency situations, participants prioritized household needs such as food, rent, and utilities rather than paying for medical care for themselves.

2) Alternative remedies used as affordable substitutes. Participants did not view alternative remedies as superior to allopathic medicine, but rather as stopgaps to abate progression or attempt symptom relief before pursuing more costly medical care.

3) Reluctance to discuss financial strain in clinical settings. Participants perceived a lack of openness and concern about affordability in doctors' offices. Embarrassment and perceived stigma contributed to their reluctance to discuss financial strain.

\section{DISCUSSION}

We found that financial strain, rather than any single social need, was the most important factor in health decisionmaking among the underserved adults we studied, and may result in non-adherence to medical recommendations that could appear to reflect lack of engagement in care. However, deviations from physician-prescribed therapies are more often the result of rational and difficult trade-offs to cope with financial strain, than a lack of interest or deficit in knowledge. Thus, patient education and counseling, while necessary, may be insufficient for improving adherence and chronic disease management in underserved populations without increased attention to also improving affordability and access to care. 
Table 1 Influence of Financial Strain on Health Decision-Making

\begin{tabular}{|c|c|}
\hline Theme/Subtheme & Sample Focus Group Quote \\
\hline $\begin{array}{l}\text { Unifying theme: Financial strain results in difficult } \\
\text { trade-offs }\end{array}$ & $\begin{array}{l}\text { [Every month, almost] nothing is left... and I have to make miracles with what is left. } \\
\text { Sometimes all I have left is } \$ 40 \ldots \text {...there's six of us and I have to buy food, other basic things I } \\
\text { need like soap, gas, and that's it. [My] kid has asthma and all the inhalers. They are very } \\
\text { expensive...what can we do? } \\
\text { My husband has diabetes, but we don't check his sugar levels because the strips are really } \\
\text { expensive. When I see him sweating, weak in bed, I know he is very, very bad. [When] he is so } \\
\text { ill he can't even get up...I tell my kids to look for coins. We start gathering coins here and there } \\
\text { to get gas and get strips to check his sugar level. Sometimes it is } 500 \text { or } 600 \text {, and sometimes it } \\
\text { just doesn't read because it's so high. }\end{array}$ \\
\hline $\begin{array}{l}\text { Subtheme 1: Trade-offs between household and } \\
\text { individual needs }\end{array}$ & $\begin{array}{l}\text { Literally, with the doctor I have to decide do I buy my insulin or feed my kids... [I] have to live } \\
\text { on insulin...but I don't want my kids starving... } \\
\text { I need to lose weight, but...I can buy organic broccoli for } \$ 3 \text { or a pizza for } \$ 8 \text { so everyone in } \\
\text { [the] family can eat, and you still have leftovers. }\end{array}$ \\
\hline $\begin{array}{l}\text { Subtheme 2: Alternative remedies used as affordable } \\
\text { substitutes for medical care }\end{array}$ & $\begin{array}{l}\text { Sometimes you prescribe yourself. A doctor's appointment is } \$ 65 \text {, and sometimes more...so you } \\
\text { try to get better with pills from Mexico, or you buy two or three pills for } \$ 2.50 \text { each to try ... } \\
\text { When there is no other choice, even knowing you are going to be owing lots of money, you go } \\
\text { to the emergency room. But you try to fight it any way you can-natural remedies, or a pill that } \\
\text { you already know has worked before. When you finally go, it's because you have tried } \\
\text { everything and [nothing worked]. }\end{array}$ \\
\hline $\begin{array}{l}\text { Subtheme 3: Reluctance to discuss economic scarcity } \\
\text { in clinical settings }\end{array}$ & $\begin{array}{l}\text { Not having money for prescriptions does come up a lot. You're embarrassed to ask for help. I've } \\
\text { gone without because of that. } \\
\text { People think you are getting everything free, and I don't like that...they think you don't got the } \\
\text { need. } \\
\text { The doctor never made me feel like it's their problem...I guess they got their own problems, and } \\
\text { this is my problem and I shouldn't lay it out on them. }\end{array}$ \\
\hline
\end{tabular}

A limitation of our single-site study is uncertain generalizability to different regions and to low-income individuals receiving other forms of assistance (i.e., housing) or no services at all.

Though clinical-community linkages are important in addressing social needs, ${ }^{3-5}$ our findings highlight overlooked opportunities for intervention within clinical settings (Table 2). First, routine screening for financial strain in clinical settings may help patients overcome reluctance to discussing costs as a barrier to care. Positive screening for financial strain should be communicated to physicians to inform and prioritize treatment recommendations that are affordable and high-value in order to maximize adherence. Second, physicians should seek to reduce the potential harms of non-adherence due to financial strain by 1) explicitly counseling patients on which medications are more versus less important and which would be safer to skip or stretch if necessary, and 2) discussing with patients the option to forego evaluation or treatment of less acute issues or lower-value care until economic conditions improve.

Table 2 Opportunities for Physicians to Mitigate Potential Health-Related Harms by Addressing Financial Strain

\begin{tabular}{|c|c|}
\hline Action & Description \\
\hline $\begin{array}{l}\text { Establish routine, periodic screening for financial strain in } \\
\text { clinical settings among at-risk individuals }\end{array}$ & $\begin{array}{l}\text { Potentially at-risk populations: } \\
\text { - Older adults } \\
\text { - Public insurance/benefits } \\
\text { - Fixed- or low-income } \\
\text { - Polypharmacy } \\
\text { - Participation in government assistance program } \\
\text { - Presence of other unmet social needs } \\
\text { Positive screen should be communicated to the treating physician to help inform } \\
\text { treatment recommendations }\end{array}$ \\
\hline Optimize affordability of medications & $\begin{array}{l}\text { - Use generics and low-cost formularies ("\$4 formularies") when possible } \\
\text { - Minimize number of medications to address potentially high cumulative costs of } \\
\text { polypharmacy } \\
\text { - Use patient assistance programs through pharmaceutical companies with caution to } \\
\text { avoid coverage gaps related to frequent eligibility renewals }\end{array}$ \\
\hline $\begin{array}{l}\text { Prioritize which medications, testing, follow-up appoint- } \\
\text { ments are high-value and more versus less important }\end{array}$ & $\begin{array}{l}\text { - Minimize polypharmacy, in-person clinic visits, and subspecialty referrals (to } \\
\text { minimize out-of-pocket costs) } \\
\text { - Prioritize urgent/acute and/or high-value medications and appointments } \\
\text { - Counsel patients on which medications/appointments should be prioritized and which } \\
\text { could potentially be stretched/skipped (i.e., high priority = insulin for symptomatic } \\
\text { hyperglycemia from diabetes vs. lower priority = vitamin D supplementation in absence } \\
\text { of osteoporosis) }\end{array}$ \\
\hline $\begin{array}{l}\text { Forego or delay testing and/or treatments that are not urgent } \\
\text { and/or high-value }\end{array}$ & $\begin{array}{l}\text { - Consider deferring primary prevention, chronic disease, and/or cancer screening } \\
\text { depending on patient financial resources and patient priorities }\end{array}$ \\
\hline
\end{tabular}


These pragmatic approaches aim to help patients prioritize high-value care and achieve adequate adherence within their financial means, rather than encouraging perfect but unattainable adherence. These strategies are foundational to addressing social needs, and to delivering truly personalized medicine to all patients.

Acknowledgements: This study was funded by the UT Southwestern Office of the President through the Program for Development and Evaluation of Model Community Health Initiatives in Dallas. Dr. Nguyen received funding support from the UT Southwestern KL2 Scholars Program (KL2 TR001103). Drs. Nguyen and Lee received support from the Agency for Healthcare Research and Quality-funded UT Southwestern Center for Patient-Centered Outcomes Research (R24 HS022418-01). The study sponsors had no role in the design or conduct of the study; collection, management, analysis, or interpretation of the data; preparation, review, or approval of the manuscript; or the decision to submit the manuscript for publication.

The authors thank the University of Dallas Community Assistance Research (CARe) partnership and Crossroads Community Services for facilitating the successful completion of this project. These findings were presented at the AcademyHealth Annual Research Meeting in June 2017 in New Orleans, Louisiana.
Corresponding Author: Oanh Kieu Nguyen, MD, MAS; , 5323 Harry Hines Blvd., Dallas, TX 75390-9169, USA

Compliance with Ethical Standards:

Conflict of Interest: The authors declare that they do not have a conflict of interest.

\section{REFERENCES}

1. Bodenheimer T, Wagner EH, Grumbach $\mathbf{K}$. Improving primary care for patients with chronic illness. JAMA. 2002;288(14):1775-79.

2. Magnan S, Fisher E, Kindig D, et al. Achieving accountability for health and health care. Minn Med. 2012;95(11):37-9.

3. Gottlieb LM, Wing H, Adler NE. A Systematic Review of Interventions on Patients' Social and Economic Needs. Am J Prevent Med. 2017;53(5):719-29.

4. Berkowitz SA, Hulberg AC, Standish S, Reznor G, Atlas SJ. Addressing Unmet Basic Resource Needs as Part of Chronic Cardiometabolic Disease Management. JAMA Intern Med. 2017;177(2):244-52.

5. Nguyen OK, Chan CV, Makam A, Stieglitz H, Amarasingham R. Envisioning a social-health information exchange as a platform to support a patient-centered medical neighborhood: a feasibility study. J Gen Intern Med. 2015;30(1):60-7. 